\title{
Abiotic Stress Upregulates the Expression of Genes Involved in PSV and Autophagy Routes ${ }^{\dagger}$
}

\author{
João Neves ${ }^{1}$, Ana Séneca ${ }^{2}$, Susana Pereira ${ }^{2} \mathbb{D}$, José Pissarra ${ }^{2} \mathbb{D}$ and Cláudia Pereira ${ }^{2, *(D)}$ \\ 1 Faculdade de Ciências da Universidade do Porto, Rua do Campo Alegre, s/n, 4169-007 Porto, Portugal; \\ jpneves99@hotmail.com \\ 2 GreenUPorto-Sustainable Agrifood Production Research Centre \& Department of Biology, \\ Faculty of Sciences, University of Porto, Rua do Campo Alegre, s/n, 4169-007 Porto, Portugal; \\ aseneca@fc.up.pt (A.S.); mspereir@fc.up.pt (S.P.); jpissarr@fc.up.pt (J.P.) \\ * Correspondence: cpereira@fc.up.pt; Tel.: +351-22-600-2153 \\ + Presented at the 1st International Electronic Conference on Plant Science, 1-15 December 2020; Available \\ online: https://iecps2020.sciforum.net/.
}

Citation: Neves, J.; Séneca, A.; Pereira, S.; Pissarra, J.; Pereira, C. Abiotic Stress Upregulates the Expression of Genes Involved in PSV and Autophagy Routes. Biol. Life Sci. Forum 2021, 4, 40. https://doi.org/ 10.3390/IECPS2020-08695

\section{Academic Editor:}

Yoselin Benitez-Alfonso

Published: 1 December 2020

Publisher's Note: MDPI stays neutral with regard to jurisdictional claims in published maps and institutional affiliations.

Copyright: () 2020 by the authors. Licensee MDPI, Basel, Switzerland. This article is an open access article distributed under the terms and conditions of the Creative Commons Attribution (CC BY) license (https:// creativecommons.org/licenses/by/ $4.0 /)$.

\begin{abstract}
Adverse conditions caused by abiotic stress modulate plant development and growth by altering morphological and cellular mechanisms. To face this problem, plants, along with physiological adaptations, developed intracellular mechanisms, including changes in protein production and trafficking or modifications of the endomembrane system. It is known that stress situations can alter protein sorting to the vacuole, changing their routes via a Golgi-independent pathway. Our goal is to evaluate the expression levels of different aspartic proteinases and well-characterized genes involved in the vacuolar pathway, in plants submitted to different abiotic stresses (osmotic, oxidative, saline and heavy metals). The results obtained point to a different response of the three aspartic proteinases under study, indicating that different, yet related, genes respond differently to different types of stress, resulting in a fine-tuned regulation. Furthermore, our results regarding the endomembrane system effectors show that AtEXO70, AtRMR1, AtSYP51, AtSYP121 and AtVTI12 are up-regulated, while AtVAMP, AtSYP23 and AtBP80 are downregulated in the same situations. This demonstrates that adverse conditions caused by abiotic stress can alter the expression of key proteins involved in the protein trafficking machinery, which can be related to the activation/deactivation of certain pathways.
\end{abstract}

Keywords: abiotic stress; aspartic proteinases; endomembrane trafficking

\section{Introduction}

Climate change stands, nowadays, as the foremost threat to human health, causing crop failures worldwide and leading to food insecurity [1]. Due to their limited locomotion, plants evolved the ability to adapt to and take advantage of changes in climate and environment [2]. Plant stress can be defined as any environmental condition that does not allow the plant to reach its full genetic potential. Abiotic stress is the main cause of the loss of quality and productivity for crops in the world. Drought, salinity, temperature and oxidative stress are often interrelated and cause similar cellular damage [3]. These diverse environmental stresses often activate signals and pathways involved in similar cellular responses: overexpression of antioxidants, accumulation of solutes, changes in protein trafficking and endomembrane remodeling [4-6]. In recent years, using high throughput screening techniques, such as microarrays and RNA sequencing, it was possible to identify many stress-related genes. These techniques provide us with important information and suggest genes among which it is possible to identify new markers for the assisted selection of varieties resistant to stress. The change in the transcriptome is still the result of a complex series of events, and our understanding of the mechanism of stress response is only partial. The identification of the specific roles of each actor in the game turns out to be an important 
factor for the genetic improvement of plants because the positive adaptation probably depends on synergistic effects and balanced interactions among proteins that are normally not related [7]. Recent experimental evidence [7,8] suggests that several classes of proteins (like aquaporins, SNARES, ATPase pumps or channels) can control specific events of membrane transport, leading to important events of cell reorganization in adverse environmental conditions. Several research groups found interesting connections between stress tolerance and membrane rearrangements not observed before, as was the case with a potassium channel selectively accumulated on small vacuoles not observed before [9] and sufficient to confer stress tolerance when overexpressed. Nonetheless the connection between the structural architecture of membranes and stress tolerance has not been sufficiently investigated. In the last decade, the proliferation of data on molecular mechanisms involved in protein trafficking has outlined subtle balances between the transport routes $[10,11]$. Understanding the physiology of plants, and crops in particular, subjected to stress has been the aim of several studies through the last decades, but none or little attention has been given to the molecular mechanisms controlling these rearrangements.

Transport and compartmentalization events of a large amount of material out of the classic vesicle traffic route have escaped full characterization. One example is the recently characterized vacuolar route mediated by the PSI (Plant Specific Insert), which was shown to follow an alternative pathway, independent of the Golgi [12]. The PSI is a unique domain, with approximately 100 amino acids, present in the primary structure of some plant aspartic proteinases (APs) $[13,14]$, which plays a role in germination, senescence, organism defense and protein turnover [15]. This sequence is responsible, before being excised, for the sorting of these APs to the protein storage vacuole (PSV) and to protein bodies, but when isolated it has the capacity to sort other proteins to the vacuole, being considered an unconventional vacuolar sorting domain [10]. When associated with proteins, PSIs can also determine their intracellular pathway depending on their glycosylation status, in other words, PSIs mediate a conventional pathway when glycosylated, but will follow a route, directly from the ER to the Golgi, when not glycosylated [12]. This process is generically indicated as unconventional trafficking, and several examples have been described [10,16-18]. Many of these unconventional routes are associated with development of stress-induced conditions, since cells need to adapt their trafficking machinery to new, challenging, scenarios.

In the context of rapid global climate change and growing production, demands are compatible with sustainable agriculture, so it is necessary to develop new selection markers that are part of more complex interactomes that, so far, have escaped phenotyping. In this context, this work aims to contribute to the understanding of mechanisms of reorganization and remodeling of plant cell endomembranes in response to abiotic stress. We evaluated the expression of three aspartic proteinases from Arabidopsis thaliana along with several well-known endomembrane system effectors, in response to different types of abiotic stress, by RT-qPCR. Our results show that some genes are upregulated when plants grow in adverse conditions, while others are downregulated, indicating a positive regulation of some trafficking routes.

\section{Experiments}

\subsection{Biological Material Preparation}

Arabidopsis thaliana (col0) seeds were germinated in Murashige and Skoog medium (MS) (Duchefa), supplemented with 1.5\% $(w / v)$ sucrose and $0.7 \%(w / v)$ bactoagar. To simulate the abiotic stress conditions, to this medium were added different concentrations of sodium chloride (saline stress: S1-50 mM and S2-100 mM), mannitol (hydric stress: $\mathrm{H} 1-50 \mathrm{mM}$ and $\mathrm{H} 2-100 \mathrm{mM}$ ), hydrogen peroxide (oxidative stress: $\mathrm{Ox}-0.5 \mathrm{mM}$ ) and zinc sulfate (heavy metal-induced stress: $\mathrm{Zn}-150 \mu \mathrm{M}$ ). Plates with seeds were maintained in a growth chamber for ten to twelve days, at $21^{\circ} \mathrm{C}$ with a photoperiod of $16 \mathrm{~h}$ light and average humidity between 50 and $60 \%$. Three biological replicates were prepared. 


\section{2. cDNA Preparation}

Total RNA preparations were obtained from $100 \mathrm{mg}$ of seedlings, using the "GeneJET Plant RNA purification Mini Kit" (Thermo Fisher Scientific, Waltham, MA, USA) according to the manufacturer instructions. Total RNA was quantified using a Nanodrop spectrophotometer (DeNovix DS-11, Bonsai Lab, Alcobendas, Spain), and its integrity was verified in an $1 \%$ agarose gel. cDNA was obtained from $2.5 \mu \mathrm{g}$ of total RNA using SuperScript IV VILO Master Mix (Thermo Fisher Scientific), following the protocol provided. Both RNA and cDNA preparations were kept at $-80^{\circ} \mathrm{C}$ until use.

\subsection{Quantitative RT-PCR}

The quantitative RT-PCR was performed in a CFX96 Real-Time System (Biorad) using PowerUp SYBR Green Master Mix (Thermo Fisher Scientific). Three biological replicates and three technical replicates were performed for each gene and situation, in $10 \mu \mathrm{L}$ reaction volume including $400 \mathrm{nM}$ of each primer and $2 \mu \mathrm{L}$ of cDNA, diluted eight times. The primer pairs used for each gene are listed in Table 1. The amplification conditions were as follows: initial denaturation $\left(95^{\circ} \mathrm{C}\right.$ for $3 \mathrm{~min}$ ) followed by 40 cycles of amplification and quantification $\left(95^{\circ} \mathrm{C}\right.$ for $10 \mathrm{~s}, 56$ for $10 \mathrm{~s}$ and $72{ }^{\circ} \mathrm{C}$ for $30 \mathrm{~s}$, with a single fluorescence measurement) and melting curve generation $\left(65^{\circ} \mathrm{C}\right.$ to $95^{\circ} \mathrm{C}$ with one fluorescence read every $\left.0.5^{\circ} \mathrm{C}\right)$. Calculation of cycle threshold $(\mathrm{Ct})$ and primer efficiency was performed using Bio-Rad CFX Maestro (version 1.0, Hercules, CA, USA) software. The analysis of the results obtained was made by relative quantification, using the same software, and by comparison with the control situation. The housekeeping genes SAND-1 and UBC9 were used as reference genes [19].

Table 1. List of genes and corresponding primer pairs used in the quantitative RT-PCR assay.

\begin{tabular}{ccc}
\hline Gene & Primer Forward & Primer Reverse \\
\hline$A t 1 g 11910$ & GGCATTGAGTCGGTGGTGGACA & TCTCACATGCAGAACACGCAGCA \\
$A t 1 g 62290$ & GGGGATTGAATCGGTGGTGGA & ACATGCAGGACAACCCGCGTCT \\
$A t 4 g 04460$ & TGCAAGGCCGTGGTGGATCA & GCGCAGACTCCAATTTGTGAGCA \\
$A t S Y P 23$ & GCAGCGTGCCCTTCTTGTGG & TCCTTGGGCAGTTGCAGCGTA \\
$A t S Y P 121$ & TCCTCCGATCGAACCAGGACCTC & TTCTCGCCGGTGACGGTGAA \\
$A t V A M P 723$ & CCCGTGGTGTGATATGTGAG & CCACAAACCGAGAGGATGAT \\
$A t V T I 12$ & GCAATGTCCGTGGAGAGGCTTGA & TGCGCATGAAGGAGGGTTTGG \\
$A t B P-80$ & GGGAGCGGCGCAGATTCTTG & GCCGGTTTCATTCGCCACCTT \\
$A t R M R 1$ & GCGAGGGAGGCACACCAGGA & TTTCCCCGGCCTTGTGGTGA \\
$A t E X O-70$ & TCCCCGATGAAACAGGCTCGTC & GCCTCCATGAAAGGGGCGTGT \\
UBC9 & TCACAATTTCCAAGGTGCTGC & TCATCTGGGTTTGGATCCGT \\
SAND-1 & AACTCTATGCAGCATTTGATCCACT & TGATTGCATATCTTTATCGCCATC \\
\hline
\end{tabular}

\section{Results}

\subsection{Expression of A. thaliana Aspartic Proteinases under Stress Conditions}

Three different, yet related, AP genes from Arabidopsis thaliana were selected for this study-At1g11910 (AP1), At1g62290 (AP2) and At4g04460 (AP3). The relative expression of each gene was analyzed by qRT-PCR in plants germinated under stress conditions. Comparing the expression patterns of the three APs genes relative to 0 , is clear that their expression in control situations is similar (Figure 1A). In order to compare the alterations in the expression patterns of these genes in the different types of stress, the results were analyzed relative to the control situation, and the genes were grouped relative to each stress condition (Figure 1B). In the saline stress, AP1 and AP3 are overexpressed in the two concentrations, while AP2 is only overexpressed in the higher concentration (Figure 1B, S1 and S2). Nevertheless, the expression of AP1 is always higher in this condition (Figure 1B, green bars). The hydric stress shows similar results in the lower concentration, while in the higher concentrations there are not significant changes in the expression (Figure 1B, $\mathrm{H} 1$ and H2). Again, AP1 and AP3 have more pronounced alterations than AP2. In the 
oxidative stress condition, AP1 is overexpressed, while AP2 shows a different behavior, being downregulated (Figure 1B, Ox). AP3 does not show significant changes. For the heavy metal stress, AP1 is upregulated, while AP3 is downregulated (Figure 1B, Zn). AP2 does not change its expression significantly. Overall, AP1 responds positively to all stress conditions tested, being its expression more pronounced in the saline and hydric stress. AP2 is the gene that varies less, having a significant response only in the higher saline condition and in oxidative stress. AP3 expression also changes with the stress but with less expression than AP1. In heavy metal-induced stress, AP1 and AP3 have antagonistic responses in terms of expression, with the first being upregulated and the second downregulated.

A

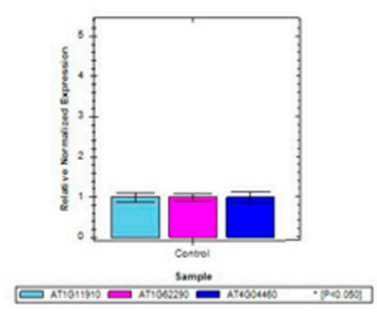

B

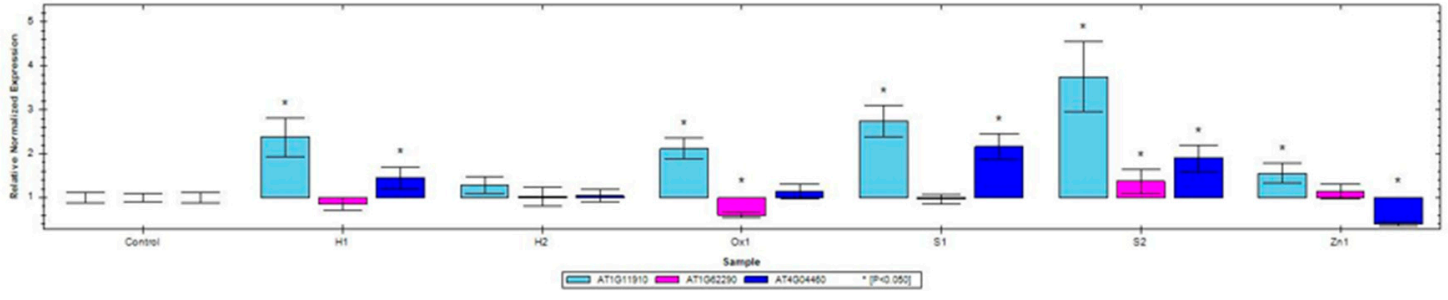

Figure 1. qRT-PCR results of AP target genes. (A) Comparison of the $3 \mathrm{AP}$ genes expression in control situation, relative to 0. (B) Expression of AP genes under stress conditions compared to control situation. * indicates statistically experimental values $(p<0.05)$.

\subsection{Expression of Endomembrane System Effectors under Stress Conditions}

Several endomembrane system-associated genes were selected for this study based on their role, protein localization and putative involvement in unconventional pathways. Their expression was evaluated in the same plants, germinated under stress conditions, as the aspartic proteinases' genes and compared to control conditions. Almost all the genes selected showed alterations in their expression being either upregulated or downregulated (Figure 2A-C). The results obtained allowed one to group these genes into two groups: one where all are upregulated (Figure 2A), and a second one where all the genes are downregulated (Figure 2C). In the first group are present AtRMR1 (At5g66160), AtEXO70 (At5g61010), AtSYP51 (At1g16240) and AtSYP121 (At3g11820). AtRMR1 is overexpressed in all situations, except in H1, being the maximum observed in $\mathrm{S} 2$ samples. AtEXO70 is overexpressed in all the samples tested, except on the heavy metal stress, where no significant differences were observed. AtSYP51 is also overexpressed with a maximum peak in the S2 saline condition. AtSYP121 presents significative overexpression values in almost all the conditions but is downregulated in H1. The second group comprises the genes AtVAMP723 (At2g33110), AtSYP23 (At4g17730) and AtBP-80 (At1g71980), which show very similar responses in all the conditions tested (Figure $2 \mathrm{C}$ ). The expression of AtVTI12 (At1g26670), despite being upregulated for all the conditions tested, was not included in any group because the relative expression is much higher, when compared to the other genes (Figure 2B). In most of the stress conditions, its expression it is roughly 10 times higher than the control (for the other genes it varies between two- and six-fold higher) and in the saline S1 condition the expression is 20- to 30-fold higher than the control. 
A

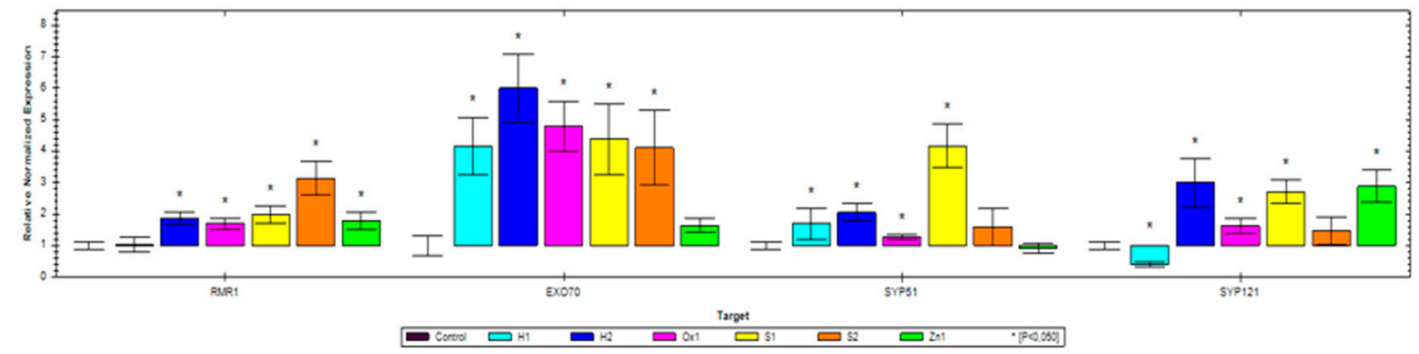

B

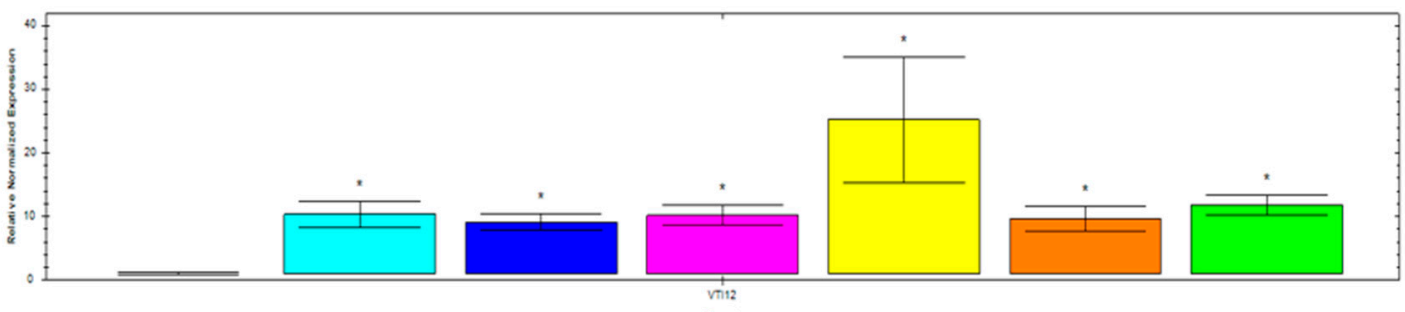

Target
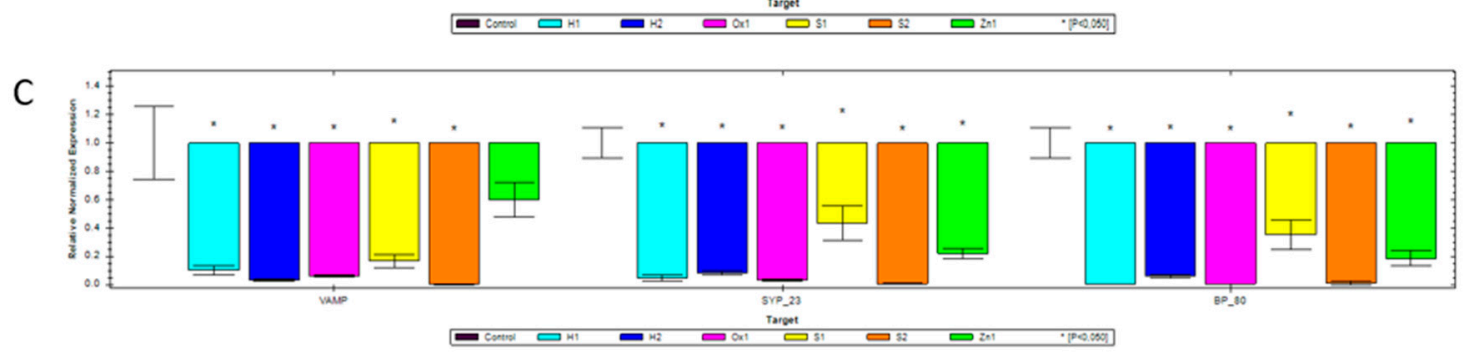

Figure 2. qRT-PCR results of endomembrane-related genes. (A) Expression of AtRMR1, AtEXO70, AtSYP51 and AtSYP121, relative to control; (B) Expression of AtVTI12, relative to control situation; (C) Expression of AtVAMP723, AtSYP23 and AtBP80, relative to control ${ }^{*}$, indicates statistically experimental values $(p<0.05)$.

\section{Discussion}

During their life cycle, plants can be exposed to several adverse conditions, including salinity, drought, extreme temperatures and heavy metal poisoning, commonly characterized as abiotic stresses. These conditions will affect several molecular, biochemical and physiological processes, resulting in delays in development and eventually senescence and cell death [20]. Because plants are not able to move, they cannot respond to environmental stimuli as animals, and adequate responses at the cellular level become particularly important. The literature is rich of data regarding plants, particularly crops, phenotypes and physiological responses to several types of abiotic stress. Despite the fact that several regulators (positive and negative) have been described so far, the regulatory molecular mechanisms entailing the basis of plant adaptation to stress remain essentially unknown.

\subsection{The 3 Typical APs from Arabidopsis thaliana Are Differentially Expressed under Stress}

Across evolution, plants developed mechanisms and responses in order to face, and adapt to, adverse environmental conditions. Plant proteases are one of the most relevant classes of proteins with a role in plant resistance to herbivores and pathogens, being recognized as key regulatory agents [21]. Their role in abiotic stress responses is by far less studied, yet some evidence points to a correlation of the expression levels of proteolytic enzymes with abiotic stress. A class of proteases that are believed to play a role in abiotic stress are aspartic proteinases (APs, EC3.4.23). APs are endopeptidases widely distributed along the plant kingdom, and like their animal counterparts, have activity at acidic $\mathrm{pH}$ and are specifically inhibited by pepstatin A [22]. Analysis of the Arabidopsis genome showed that this plant has 51 genes coding for APs, which were grouped, based on their domain organization, into three different groups: typical, atypical and nucellin-like [23]. A distinguishing feature of typical APs is the presence of a 100 aminoacid long insertion, termed Plant Specific Insert (PSI), that is involved in vacuolar 
sorting and is able to induce vesicle leakage, suggested to have a role in plant defense against pathogens [10,24-26]. In this study, we focused our attention on the A1 group of typical APs, composed of three different genes: At1g11910, At1g62290 and At4g04460. We examined the expression of each gene in seedlings germinated under different abiotic conditions and compared their expression in relation to control situations. It is worth mentioning that all three genes revealed similar expression levels in control seedlings, indicating that the changes in expression observed in this study are only related to the experimental conditions. Interestingly, all three AP genes behave differently in response to different types of stress, and in some situations their response is even antagonistic. At1g11910 expression is enhanced when compared to the other two genes, especially in the saline and hydric stress conditions. A study performed several years ago regarding APs expression in different plant tissues [27] revealed that At1g11910 mRNA has a more ubiquitous expression than the other two, which have a more restricted pattern: At1g62290 expression was detected in seeds and At4g04460 in flowers. This differential expression in planta can explain the more remarkable response observed for At1g11910 since in this study we obtained the mRNA from seedlings. It can also point to a more important role for this AP in plant cells' response to abiotic stress and is a good candidate for further studies regarding plant tolerance or adaptation to adverse conditions. Several plant APs have been already implicated in defense of or tolerance to abiotic stress associated with water deficit or high salinity. Contour-Ansel and co-workers [28] showed that a typical AP from common bean was highly implicated during water stress being constitutively expressed in drought-tolerant cultivars. Another research paper focusing on a grape AP demonstrated that Arabidopsis plants overexpressing that gene showed enhanced tolerance to salt and drought stress, during germination, seedling and mature stage [29]. Although hand salt and drought stress is reasonably well documented, the role of proteinases in oxidative and heavy metal stress has not been explored till date. The data obtained in our study regarding these two types of stress is quite intriguing if we consider the results obtained for At1g62290 and At4g04460: in the oxidative stress, the first is downregulated, while the expression of the second remains unaltered, and the opposite scenario is observed for the heavy metal stress. At this point, the significance of these results is unclear, since not much information is available regarding either these two APs or the effect of these conditions in proteases expression in general. However, it would be worth exploring in more detail these observations in order to understand how and why this specificity exists and if it could be related to the expression in the plant and/or their intracellular localization or pathways.

\subsection{Genes Involved in the Path to the PSV Are Positively Regulated under Stress}

Endomembrane trafficking is an essential process for all eukaryotic cells as several proteins are constantly being produced and need to be delivered to the correct location in order to exert their function. The molecular mechanisms and effectors underlying such pathways have been extensively studied over the years, and nowadays very detailed information is available [30]. The endomembrane system in plants needs to be constantly adapting either to morphological demands related to development or to a changing environment. Thus, trafficking pathways and their associated machinery are tightly linked to stress signaling pathways, for the de novo expression and/or re-location of stress-related proteins [31]. Here, we show the expression of several endomembrane-related genes involved in different vacuolar pathways during abiotic stress conditions. The eight genes selected for this work clustered in two groups: one where the genes were upregulated in all the stress situations (AtRMR1, AtEXO70, AtSYP51, AtSYP121 and AtVTI12) and other where the genes were downregulated for all the stress conditions (AtVAMP723, AtSYP23 and AtBP80). Remarkably, most of the genes that are overexpressed are associated with the route to the protein storage vacuole (PSV). RMR1 is a vacuolar sorting receptor found to localize to the Golgi, TGN and PSVs and transports proteins that carry a C-terminal vacuolar sorting determinant (ctVSD). Is has been implicated in the sorting of storage proteins to the PSV via precursor accumulating vesicles (PACs) $[18,32,33]$. BP80, another vacuolar 
sorting receptor, is responsible for protein transport to the lytic vacuole and through a different pathway and mechanism: BP80 recognizes a typical NPIR motif present at the $\mathrm{N}$-terminus of vacuolar proteins and mediates trafficking through clathrin-coated vesicles (CCVs) $[33,34]$. In our study, AtBP80 is clearly downregulated for all the stress conditions analyzed. Taking together the results obtained for these two vacuolar receptors, it is likely that the vacuolar transport is biased towards the PSV pathway. This hypothesis is quite exciting as it indicates that plant cells are able to shift their sorting mechanisms towards a more restrained state and probably start to accumulate storage molecules to face the adverse conditions. This hypothesis gains more strength when we look at the other genes that are upregulated in this study. SYP51 and VTI12 belong to different functional classes of SNARE proteins and both have been shown to be positive regulators of proteins with a CtVSD in their sorting to PSVs, as was demonstrated for chitinase A [35-37]. To our surprise, AtVTI12 showed a much higher increase in relative expression when compared to other genes tested, especially during salt stress (approx. 30 times higher). This increase must be related to other function of this protein other than mediating protein trafficking to the PSV. It was demonstrated that VTI12 also plays a role in the plant autophagy pathway [38], a process that plays a crucial role in plants adaptation to adverse conditions either derived from environmental stress or pathogen attack [39]. Thus, it is not surprising that members of this pathway are upregulated in such process. SYP121 is another SNARE that we found to be upregulated under stress conditions. This protein localizes at the plasma membrane and has been implicated in stomatal closure and $\mathrm{K}+$ channel activity following stress signals [40,41]. SYP121 is therefore important in the control of cellular volume and osmotic adjustment, which correlates well with the results observed for the salt and drought stress since the increase in gene expression in these conditions was more obvious than in oxidative or heavy metal stress. The last gene found to be upregulated in this study was AtEXO70, a key player in exocyst-positive organelle (EXPO) formation. It has been involved in autophagy processes and in the vacuolar pathway in animals and plants [42]. Similarly to what we observed for abiotic stress, some EXO70 isoforms were found to be upregulated under biotic stress conditions [43]. As for VTI12, the role of this protein in the autophagic process and/or in EXPO could be important for the protein degradation and membrane remodeling occurring during stress events. The expression of two other genes was tested under this study: AtSYP23 and AtVAMP723. Both showed to be downregulated in all stress conditions. Despite not being as well characterized as their homologues, the proteins coded by these two genes have curious localizations: most of the SNARE proteins are found at the post-Golgi level; however, VAMP723 is found at the Endoplasmic Reticulum and SYP23 is a cytoplasmic protein, which lacks a transmembrane domain [44]. At this point, it is not possible to assess the biological relevance of the observed behavior of these two genes in abiotic stress conditions; nevertheless, it is worth to evaluate the expression of other members of their family in order to understand their role in this process.

\section{Conclusions}

It is known that adverse environmental conditions challenge the endomembrane organization of the cell that need to readjust protein biogenesis and trafficking pathways. In the present study, we analyzed the expression of several genes involved in the vacuolar pathway during stress conditions. From the results obtained, we conclude that the vacuolar pathway to the protein storage vacuole is enhanced, as evidenced by the upregulation of the aspartic proteinases' genes and by vacuolar receptors and members of the SNARE family involved in this route. Additionally, the autophagic pathway seems to be enhanced as well, confirming its role during abiotic stress conditions. In order to sustain the data presented here, it would be interesting to test the expression and localization of other genes involved in the pathways here described.

Supplementary Materials: The poster presentation is available online at https: / / www.mdpi.com/ article/10.3390/IECPS2020-08695/s1. 
Author Contributions: J.N., A.S., S.P. and C.P. conceived and designed the experiments; J.N. performed the experiments; J.N., A.S. and C.P. analyzed the data; J.P. contributed reagents and materials; J.N. and C.P. wrote the paper; and A.S., S.P. and J.P. reviewed the manuscript. All authors have read and agreed to the published version of the manuscript.

Institutional Review Board Statement: Not applicable.

Informed Consent Statement: Not applicable.

Acknowledgments: This research was supported by and in the frame of the scientific project PTDC/BIA-FBT/32013/2017, funded by the Portuguese foundation FCT, and also within the scope of UIDB/05748/2020 and UIDP/05748/2020.

Conflicts of Interest: The authors declare no conflict of interest. The founding sponsors had no role in the design of the study; in the collection, analyses, or interpretation of data; in the writing of the manuscript; or in the decision to publish the results.

\section{References}

1. Mousavi-Derazmahalleh, M.; Bayer, P.E.; Hane, J.K.; Valliyodan, B.; Nguyen, H.T.; Nelson, M.N.; Erskine, W.; Varshney, R.K.; Papa, R.; Edwards, D. Adapting legume crops to climate change using genomic approaches. Plant Cell Environ. 2019, 42, 6-19. [CrossRef]

2. Kalinowska, K.; Isono, E. All roads lead to the vacuole-Autophagic transport as part of the endomembrane trafficking network in plants. J. Exp. Bot. 2018, 69, 1313-1324. [CrossRef]

3. Zhu, J.-K. Salt and droght stress signal transduction in plants. Annu. Rev. Plant Biol. 2002, 53, 247-273. [CrossRef] [PubMed]

4. Cushman, J.C.; Bohnert, H.J. Genomic approaches to plant stress tolerance. Curr. Opin. Plant Biol. 2000, 3, 117-124. [CrossRef]

5. Moellering, E.R.; Benning, C. Galactoglycerolipid metabolism under stress: A time for remodeling. Trends Plant Sci. 2011, 16, 98-107. [CrossRef] [PubMed]

6. Bassham, D.C.; Laporte, M.; Marty, F.; Moriyasu, Y.; Ohsumi, Y.; Olsen, L.J.; Yoshimoto, K. Autophagy in Development and Stress Responses of Plants. Autophagy 2006, 2, 2-11. [CrossRef]

7. Chevalier, A.S.; Chaumont, F. Trafficking of Plant Plasma Membrane Aquaporins: Multiple Regulation Levels and Complex Sorting Signals. Plant Cell Physiol. 2015, 56, 819-829. [CrossRef]

8. Hachez CLaloux, T.; Reinhardt, H.; Cavez, D.; Degand, H.; Grefen, C.; De Rycke, R.; Inzé, D.; Blatt, M.R.; Russinova, E.; Chaumont, F. Arabidopsis SNAREs SYP61 and SYP121 coordinate the trafficking of plasma membrane aquaporin PIP2;7 to modulate the cell membrane water permeability. Plant Cell 2014, 26, 3132-3147. [CrossRef]

9. Ahmad, I.; Devonshire, J.; Mohamed, R.; Schultze, M.; Maathuis, F.J.M. Overexpression of the potassium channel TPKb in small vacuoles confers osmotic and drought tolerance to rice. New Phytol. 2016, 209, 1040-1048. [CrossRef]

10. Pereira, C.; Pereira, S.; Satiat-Jeunemaitre, B.; Pissarra, J. Cardosin A contains two vacuolar sorting signals using different vacuolar routes in tobacco epidermal cells. Plant J. 2013, 76, 87-100. [CrossRef]

11. Jürgens, G.; Pimpl, P. Plant membrane trafficking is coming of age. Semin. Cell Dev. Biol. 2018, 80, 83-84. [CrossRef]

12. Vieira, V.; Peixoto, B.; Pereira, S.; Pissarra, J.; Pereira, C. N-Linked Glycosylation Modulates. Plants 2019, 8, 312. [CrossRef]

13. Bryksa, B.C.; Grahame, D.A.; Yada, R.Y. Comparative structure-function characterization of the saposin-like domains from potato, barley, cardoon and Arabidopsis aspartic proteases. Biochim. Biophys. Acta Biomembr. 2017, 1859, 1008-1018. [CrossRef] [PubMed]

14. Cheung, L.K.Y.; Dupuis, J.H.; Dee, D.R.; Bryksa, B.C.; Yada, R.Y. Roles of Plant-Specific Inserts in Plant Defense. Trends Plant Sci. 2020, 25, 682-694. [CrossRef]

15. Mazorra-Manzano, M.A.; Tanaka, T.; Dee, D.R.; Yada, R.Y. Structure-function characterization of the recombinant aspartic proteinase A1 from Arabidopsis thaliana. Phytochemistry 2010, 71, 515-523. [CrossRef] [PubMed]

16. Robinson, D.G.; Ding, Y.; Jiang, L. Unconventional protein secretion in plants: A critical assessment. Protoplasma 2016, 253, 31-43. [CrossRef] [PubMed]

17. Pompa, A.; De Marchis, F.; Pallotta, M.T.; Benitez-Alfonso, Y.; Jones, A.; Schipper, K.; Moreau, K.; Žárský, V.; Di Sansebastiano, G.P.; Bellucci, M. Unconventional transport routes of soluble and membrane proteins and their role in developmental biology. Int. J. Mol. Sci. 2017, 18, 703. [CrossRef]

18. Di Sansebastiano, G.; Barozzi, F.; Piro, G.; Denecke, J.; de Marcos Lousa, C. Trafficking routes to the plant vacuole: Connecting alternative and classical pathways. J. Exp. Bot. 2018, 69, 79-90. [CrossRef]

19. Wang, W.; Vinocur, B.; Altman, A. Plant responses to drought, salinity and extreme temperatures: Towards genetic engineering for stress tolerance. Planta 2003, 218, 1-14. [CrossRef]

20. Brzin, J.; Kidrič, M. Proteinases and their inhibitors in plants: Role in normal growth and in response to various stress conditions. Biotechnol. Genet. Eng. Rev. 1996, 13, 421-468. [CrossRef]

21. Simões, I.; Faro, C. Structure and function of plant aspartic proteinases. Eur. J. Biochem. 2004, 271, 2067-2075. [CrossRef]

22. Faro, C.; Gal, S. Aspartic Proteinase Content of the Arabidopsis Genome. Curr. Protein Pept. Sci. 2005, 6, 493-500. [CrossRef] [PubMed] 
23. Egas CLavoura, N.; Resende, R.; Brito, R.M.; Pires, E.; de Lima, M.C.; Faro, C. The Saposin-like Domain of the Plant Aspartic Proteinase Precursor Is a Potent Inducer of Vesicle Leakage. J. Biol. Chem. 2002, 275, 38190-38196. [CrossRef] [PubMed]

24. Terauchi, K.; Asakura, T.; Ueda, H.; Tamura, T.; Tamura, K.; Matsumoto, I.; Misaka, T.; Hara-Nishimura, I.; Abe, K. Plant-specific insertions in the soybean aspartic proteinases, soyAP1 and soyAP2, perform different functions of vacuolar targeting. J. Plant Physiol. 2006, 163, 856-862. [CrossRef]

25. Frey, M.E.; D'Ippolito, S.; Pepe, A.; Daleo, G.R.; Guevara, M.G. Transgenic expression of plant-specific insert of potato aspartic proteases (StAP-PSI) confers enhanced resistance to Botrytis cinerea in Arabidopsis thaliana. Phytochemistry 2018, 149, 1-11. [CrossRef]

26. Chen, X.; Pfeil, J.E.; Gal, S. The three typical aspartic proteinase genes of Arabidopsis thaliana are differentially expressed. Eur. J. Biochem. 2002, 269, 4675-4684. [CrossRef]

27. Contour-Ansel, D.; Torres-Franklin, M.L.; Zuily-Fodil, Y.; de Carvalho, M.H.C. An aspartic acid protease from common bean is expressed 'on call' during water stress and early recovery. J. Plant Physiol. 2010, 167, 1606-1612. [CrossRef]

28. Guo, R.; Zhao, J.; Wang, X.; Guo, C.; Li, Z.; Wang, Y.; Wang, X. Constitutive expression of a grape aspartic protease gene in transgenic Arabidopsis confers osmotic stress tolerance. Plant Cell. Tissue Organ Cult. 2015, 121, 275-287. [CrossRef]

29. Jürgens, G. Membrane trafficking in plants. Annu. Rev. Cell Dev. Biol. 2004, 20, 481-504. [CrossRef]

30. Wang, X.; Xu, M.; Gao, C.; Zeng, Y.; Cui, Y.; Shen, W.; Jiang, L. The roles of endomembrane trafficking in plant abiotic stress responses. J. Integr. Plant Biol. 2020, 62, 55-69. [CrossRef] [PubMed]

31. Shen, Y.; Wang, J.; Ding, Y.; Lo, S.W.; Gouzerh, G.; Neuhaus, J.M.; Jiang, L. The rice RMR1 associates with a distinct prevacuolar compartment for the protein storage vacuole pathway. Mol. Plant 2011, 4, 854-868. [CrossRef]

32. Xiang, L.; Etxeberria, E.; Van Den Ende, W. Vacuolar protein sorting mechanisms in plants. FEBS J. 2013, 280, 979-993. [CrossRef]

33. Lee, Y.; Jang, M.; Song, K.; Kang, H.; Lee, M.H.; Lee, D.W.; Zouhar, J.; Rojo, E.; Sohn, E.J.; Hwang, I. Functional identification of sorting receptors involved in trafficking of soluble lytic vacuolar proteins in vegetative cells of Arabidopsis. Plant Physiol. 2013, 161, 121-133. [CrossRef]

34. Stigliano, E.; Sansebastiano, G.-P.; Neuhaus, J.-M. Contribution of Chitinase A's C-Terminal Vacuolar Sorting Determinant to the Study of Soluble Protein Compartmentation. Int. J. Mol. Sci. 2014, 15, 11030-11039. [CrossRef]

35. Di Sansebastiano, G.P.; Faraco, M.; Zouhar, J.; Dalessandro, G. The study of plant SNAREs specificity in vivo. Plant Biosyst. 2009, 143, 621-629. [CrossRef]

36. Sanmartín, M.; Ordóñez, A.; Sohn, E.J.; Robert, S.; Sánchez-Serrano, J.J.; Surpin, M.A.; Raikhel, N.V.; Rojo, E. Divergent functions of VTI12 and VTI11 in trafficking to storage and lytic vacuoles in Arabidopsis. Proc. Natl. Acad. Sci. USA 2007, 104, 3645-3650. [CrossRef] [PubMed]

37. Surpin, M.; Zheng, H.; Morita, M.T.; Saito, C.; Avila, E.; Blakeslee, J.J.; Bandyopadhyay, A.; Kovaleva, V.; Carter, D.; Murphy, A.; et al. The VTI Family of SNARE Proteins Is Necessary for Plant Viability and Mediates Different Protein Transport Pathways. Plant Cell 2003, 15, 2885-2899. [CrossRef]

38. Han, S.; Yu, B.; Wang, Y.; Liu, Y. Role of plant autophagy in stress response. Protein Cell 2011, 2, 784-791. [CrossRef] [PubMed]

39. Eisenach, C.; Chen, Z.H.; Grefen, C.; Blatt, M.R. The trafficking protein SYP121 of Arabidopsis connects programmed stomatal closure and $\mathrm{K}+$ channel activity with vegetative growth. Plant J. 2012, 69, 241-251. [CrossRef] [PubMed]

40. Besserer, A.; Burnotte, E.; Bienert, G.P.; Chevalier, A.S.; Errachid, A.; Grefen, C.; Blatt, M.R.; Chaumont, F. Selective regulation of maize plasma membrane aquaporin trafficking and activity by the SNARE SYP121. Plant Cell 2012, 24, 3463-3481. [CrossRef]

41. Žárský, V.; Sekereš, J.; Kubátová, Z.; Pečenková, T.; Cvrčková, F. Three subfamilies of exocyst EXO70 family subunits in land plants: Early divergence and ongoing functional specialization. J. Exp. Bot. 2020, 71, 49-62. [CrossRef] [PubMed]

42. Pečenková, T.; Potocká, A.; Potocký, M.; Ortmannová, J.; Drs, M.; Janková Drdová, E.; Pejchar, P.; Synek, L.; Soukupová, H.; Žárský, V.; et al. Redundant and Diversified Roles Among Selected Arabidopsis thaliana EXO70 Paralogs During Biotic Stress Responses. Front. Plant Sci. 2020, 11, 1-14. [CrossRef] [PubMed]

43. Gu, X.; Brennan, A.; Wei, W.; Guo, G.; Lindsey, K. Vesicle Transport in Plants: A Revised Phylogeny of SNARE Proteins. Evol. Bioinform. 2020, 16, 1176934320956575. [CrossRef] [PubMed]

44. Shirakawa, M.; Ueda, H.; Shimada, T.; Koumoto, Y.; Shimada, T.L.; Kondo, M.; Takahashi, T.; Okuyama, Y.; Nishimura, M.; Hara-Nishimura, I. Arabidopsis Qa-SNARE SYP2 proteins localized to different subcellular regions function redundantly in vacuolar protein sorting and plant development. Plant J. 2010, 64, 924-935. [CrossRef] [PubMed] 